\title{
Participação das crianças em projeto político-social elaborado por adultos: a Plenarinha no Distrito Federal
}

\author{
Etienne Baldez Louzada Barbosa ${ }^{1}$ \\ ORCID: 0000-0001-6780-3148 \\ Monique Aparecida Voltarelli ${ }^{1}$ \\ ORCID: 0000-0003-2605-0930
}

\section{Resumo}

Falar de participação infantil remete a distintos graus e possibilidades em que as crianças tenham suas opiniões consideradas e possam exercer a cidadania por meio de processos iniciados por adultos ou por elas, mas que haja relações de equilíbrio de poder e parceria. Frequentemente, a participação das crianças é referida em projetos de forma decorativa, usando as falas das crianças, para reafirmar que elas estiveram envolvidas nos processos e tiveram suas vozes consideradas. Entretanto, essa ilustração remete apenas a etapas de não participação das crianças e que demandam repensar conceitos que envolvem esse complexo processo. Atentando-se a essas questões, o presente texto procurou compreender como ocorre a participação das crianças pequenas na Plenarinha no Distrito Federal proposta pela Secretaria de Estado de Educação. Por meio de uma pesquisa qualitativa, que fez uso de análise documental, buscou-se verificar nos textos oficiais publicados e notícias vinculadas no jornal Correio Braziliense se o programa considerava a voz das crianças na implementação de mudanças na educação infantil. Após análise dos documentos, pode-se referir que o programa não contemplou as infâncias presentes nas instituições de educação infantil, bem como ocultou nos documentos como os processos de participação das crianças ocorreram. Nota-se que a perspectiva adultocêntrica colocase como um impeditivo para legitimar a ação social das crianças, que têm sua competência comparada a padrões adultos, e que acabam por invisibilizar esse grupo minoritário, que historicamente esteve à margem da participação social.

\section{Palavras-chave}

Participação infantil - Plenarinha - Educação infantil.

1- Universidade de Brasília, Brasília, DF, Brasil. Contatos: blb_etienne@hotmail.com; moniquevoltarelli@yahoo.com.br. 


\section{Children's participation in a social-political project conducted by adults: the Plenarinha in the Federal District}

\section{Abstract}

Talking about children's participation leads to different degrees and possibilities in which children would have their opinions taken into account and practice citizenship through processes started by adults or by the children themselves. Instead, there should be balanced power relations and partnership. Often, children's participation is decoratively mentioned in projects that utilize the children's speech only to reassert that children were involved in processes and had their voices heard. However, such illustration has to do only with the absence of children's participation and the concepts around this complex process should be reassessed. Paying attention to that, this paper has sought to understand how small children participate in the Plenarinha (little plenary) in the Federal District as proposed by its Education Department. By means of a qualitative research utilizing documental analysis, the aim was to screen the official texts that had been published and the news stories appearing in the newspaper Correio Braziliense to check whether the program took the children's voice into consideration when implementing changes in child education. Upon the analysis of the documents, it may be said that the program did not include the childhoods present in the child education's institutions and, also, the program's documents concealed how the processes of children's participation took place. It is noted that the adult-centered perspective represents an obstacle to legitimate the children's social action, as children have their competency compared to adult standards. This eventually makes this minority group invisible, as they have historically been marginalized from social participation.

\section{Keywords}

Childhood participation - Plenarinha - Early childhood education.

\section{Introdução}

Quando pensamos nas relações travadas com e entre as crianças, existe o consenso de que os pequenos, que vivem o tempo da infância, são atores sociais, que constituem cultura nas trocas realizadas com o meio e são pela cultura constituídos. Coadunando com o que Souza (2007, p. 74) reforça, aqui se considera "a criança como sujeito social individual, que carrega desde o nascimento as expectativas sociais e ao desvendar o mundo e mergulhado nele aprende ou pode se constituir Indivíduo", ou, utilizando a metáfora, "como espécie de um cristal, é pedra pois sedimentada pela formação geológica, todavia o desenho toma forma própria”. (SOUZA, 2007, p. 74) 
A criança tem muito a dizer, a expressar, sendo importante o tempo que se dispõe para escutá-la de forma sensivel e respeitosa. Realizar essa escuta qualificada é o grande desafio para os adultos que interagem diretamente com as crianças. E, mais do que isso, oportunizar que a fala e as proposições por elas engendradas virem uma ação ou uma política é o segundo grande embate. Freire (1996) observa que o processo de fala e de escuta é um compromisso que requer disciplina, principalmente com o silêncio daquele que se faz de ouvidos, para que ocorra uma "comunicação dialógica”. Em suas palavras:

[...] o primeiro sinal de que o sujeito que fala sabe escutar é a demonstração de sua capacidade de controlar não só a necessidade de dizer a sua palavra, mas também o gosto pessoal, profundamente respeitável, de expressá-la. (FREIRE, 1996, p. 60).

Escutar as crianças envolve respeitar e compreender suas falas a partir de seus referenciais e não em nome de um futuro hipotético que elas ainda não compreendem (KORCZAK, 1983), ou seja, demanda considerar as visões e experiências das crianças em todas as suas linguagens corporais e expressivas a fim de preservar a singularidade da infância. Essa escuta ocorre por meio de uma aprendizagem coletiva, colaborativa e democrática e que convoca repensar o papel das crianças na sociedade, para que se possa valorizar sua participação social e política, enquanto cidadã no presente e portadora de direitos.

Muito se fala em participação das crianças e a necessidade de escuta sensível, mas como fazê-la? Buscando por significados dessa ação, Rinaldi (2016, p. 236) discorre acerca de alguns pontos fundamentais para realizar a escuta das crianças, a saber: a) deve ser compreendida como um verbo ativo que envolve dar uma interpretação à fala e valorizar aqueles que serão escutados; b) exige uma consciência e suspensão de julgamentos e conceitos; c) demanda tempo de diálogo e reflexão interna; d) precisa ser aberta e ter sensibilidade para compreender as diversas formas de comunicação e expressão; e) exige abertura à mudança para que se possa valorizar o desconhecido e superar o questionamento de nossas certezas; e f) precisa ocorrer em um contexto de escuta, para que se possa aprender a ouvir, narrar e negociar as diferentes perspectivas na tomadas de decisão.

Para pensar em ações comprometidas com as crianças, a postura mais coerente deveria pautar-se em propostas desenvolvidas com elas e não somente para elas. Para tanto, é necessário considerar não apenas a dimensão etária, mas articular às dimensões de gênero, classe social e etnia (JAMES; PROUT, 1990). As infâncias são vividas em contextos heterogêneos e ao indicar ações direcionadas a elas, é necessário analisar as implicações para que as crianças possam participar como agentes sociais, com competência para ação, comunicação e trocas culturais. (HUTCHBY; MORAN-ELLIS, 1998).

A esta discussão cabe acrescentar que, do ponto de vista teórico, a participação infantil frequentemente é limitada pelas imposições adultas e/ou pela forma como esses entendem equivocadamente, por assim dizer, o conceito. A participação social das crianças pode ser compreendida por meio de múltiplas defınições, todavia, para este texto, foram selecionadas as contribuições de Hart (1992, p. 5), ao defini-la como "o processo de compartilhamento de decisões que afetam cada vida e a vida da comunidade em que se vive", indicando aspectos tanto pessoais quanto coletivos. 
As possibilidades de participação infantil podem ocorrer em diversos lugares, tais como "ambientes institucionais centrais - locais de escolarização, de cuidado, comunidade; periféricos - o mercado, a rua, a formação política; privados - esferas particulares, familiar; virtuais" (WYNESS, 2014, p. 53) e por diferentes níveis que foram definidos por Hart (1992) por meio de uma escada da participação. Essa escada tem oito níveis, sendo que nos três primeiros degraus a criança não participa e nos cinco restantes ela tem algum grau de participação em formato de relações e parcerias estabelecidas entre as crianças e adultos. Cabe mencionar que um degrau não conduz ao seguinte e sim referem-se aos diferentes objetivos traçados em relação ao envolvimento da participação das crianças.

Os três primeiros degraus são compostos por elementos que não consideram a participação das crianças e são nomeados como manipulação, decoração e tokenismo (indicação falsa de participação). Embora esses níveis não signifiquem a participação real das crianças, eles são vistos com frequência em projetos por dar a voz a elas e permitir que, de certo modo, façam escolhas e indiquem seus pontos de vistas. Entretanto, esses não são considerados nas tomadas de decisão e não influenciam a perspectiva dos adultos. Os degraus seguintes são compostos pelo que o autor denomina de participação designada, mas informada; consultada e informada; iniciada por adultos, mas com decisões partilhadas com as crianças; iniciado e dirigido pelas crianças e, por fim, o último degrau seria pelas iniciativas das crianças, mas com decisões partilhadas com os adultos. Todavia, essa organização não é uma simples forma de medir a participação das crianças nos diversos aspectos e possibilidades que elas ocorrem, mas é uma maneira de pensar os cenários que têm considerado a participação infantil.

Além disso, cabe destacar que nas obras de Hart (1992) e Taylor e Percy-Smith (2008), elucida-se que, dentre as principais problemáticas em relação aos projetos que visam a considerar a participação das crianças, estão o abuso de poder e a priorização da perspectiva adulta. Esses elementos têm impedido o sucesso de projetos com as crianças por desconsiderarem os seus interesses pela justificativa protecionista de que os adultos sabem o que é melhor para elas.

Ao atentar-se para a relação dialógica e propositiva que decorre da fala das crianças com adultos, bem como aos projetos que vêm considerando a participação das crianças na sociedade 2 , aqui se propõe compreender a Plenarinha no Distrito Federal (DF) e a participação dos pequenos nesse programa da Secretaria de Estado de Educação do Distrito

\footnotetext{
2- Oliveira; Reis (2013) pontuam sobre processos participativos envolvendo crianças e jovens e afirmam que "um dos exemplos pioneiros de participação de crianças na governança foi registrado na cidade de Barra Mansa, que de 1997 a 2000 manteve um conselho orçamentário participativo que incluía 36 crianças" (OLIVEIRA; REIS, 2013, p. 83). As autoras elencam outros processos, como: Fórum Crianças e Clima; I Seminário "A Voz dos Adolescentes do Semiárido"; Revista Descolad@s, Deixa eu falar!; Prêmio das Crianças do Mundo pelos Direitos da Criança (WCPRC) e Orçamento Participativo Criança, do município de São Paulo. Este último, conhecido como OP Criança, foi implementado pela Secretaria Municipal de Educação, em parceria com a Coordenadoria do Orçamento Participativo da cidade de São Paulo e com o Instituto Paulo Freire. 0 projeto volta-se para o protagonismo das crianças e adolescentes no espaço escolar, que participam de etapas decisórias de como aplicar parte do orçamento do município. "O primeiro passo foi a Leitura do Mundo. A partir dela, chegamos ao conhecimento das necessidades, sonhos, desejos, carências e interesses das crianças, adolescentes e jovens. Chegamos às situações significativas de seus contextos. Em um processo dialógico, lúdico e dinâmico, fomos problematizando e aprofundando a compreensão dos aspectos mencionados por elas. Amadurecendo as ideias, fomos chegando às possíveis propostas a serem apresentadas para a cidade e para a educação". (GOMES, 2004, p. 60).
} 
Federal (SEEDF), por meio dos documentos oficiais disponibilizados e notícias vinculadas no jornal Correio Braziliense.

Como o nome já permite aventar, a Plenarinha, realizada com crianças das instituições de educação infantil do Distrito Federal, é uma assembleia ou sessão plena em que se discute determinado tema e, a partir da escuta das crianças, deveriam ser implementadas as ações no currículo. A Plenarinha comparece no site da SEEDF como um "Programa Educação Infantil” (PEI), com a descrição da segunda até a sétima realizada, entre os anos de 2013 a 2019 (PROGRAMA..., s/d).

Algumas questões nortearam a escrita deste trabalho, atreladas ao objetivo central aqui demarcado: como se organiza e como se escolhe o tema de cada ano a ser debatido pelas crianças na Plenarinha? Como as crianças efetivamente fazem parte desse processo? Partindo dessas questões e formulando outras, o presente artigo volta-se para dois aspectos: apresentação do programa Plenarinha e indicação da participação das crianças.

\section{Plenarinha: "escuta sensível e atenta às crianças"}

As explicações da primeira Plenarinha estão descritas no site do programa do governo do Distrito Federal, Criança Candanga, dizendo que é um projeto pedagógico da Secretaria de Estado de Educação (SEEDF), desenvolvido pela Subsecretaria de Educação Básica/ Diretoria de Educação Infantil, desde 2013, em todas as unidades públicas e instituições parceiras que ofertam educação infantil. 0 quadro a seguir permite a visualização das plenarinhas existentes:

Quadro 1 - As plenarinhas no Distrito Federal

\begin{tabular}{cccc}
\hline Ano & $\vdots$ & Temas \\
\hline 2013 & $\vdots$ & I - Plenarinha do Currículo \\
\hline 2014 & $\vdots$ & II - Eu, cidadão - da Plenarinha à Participação \\
\hline 2015 & $\vdots$ & III - Escuta sensível às crianças: uma possibilidade para a (re)construção do Projeto Político Pedagógico \\
\hline 2016 & $\vdots$ & IV - A cidade (e o campo) que as crianças querem \\
\hline 2017 & $\vdots$ & V - A criança na natureza: por um crescimento sustentável \\
\hline 2018 & $\vdots$ & VI - Universo do Brincar \\
\hline 2019 & $\vdots$ & VII - Brincando e encantando com histórias \\
\hline
\end{tabular}

Fonte: SEEDF e Criança Candanga.

Pelos títulos das Plenarinhas destacam-se cinco eixos de discussão em sete anos de existência: currículo, cidadania, meio ambiente, brincar e literatura. Todos eles estão 
contemplados nas normatizações atuais para a primeira etapa da educação básica. Mas, quem escolhe o tema de uma Plenarinha? Em 2011, ocorreram as plenárias acerca do currículo para educação infantil, "com parceria entre as Coordenações Regionais de Ensino (CRE), instituições educacionais, documentos norteadores da Subsecretaria de Educação Básica (SUDEB)" e, no ano seguinte, as discussões nos Grupos de Trabalho sobre o currículo "foram organizadas em cadernos, denominado de Currículo em Movimento", sendo as plenárias específicas realizadas em 2013 (CURRÍCULO..., s/d, p. 12-13). A I Plenarinha com as crianças ocorreu também em 2013, coadunando com o movimento de discussão e constituição do currículo entre os profissionais e estudiosos da educação infantil no Distrito Federal.

Ao acompanhar as notícias acerca da Plenarinha nos jornais do Distrito Federal, é possível encontrar algumas menções e, entre elas, a reportagem intitulada Unesco quer que as escolas intensifiquem atenção aos problemas ambientais. Resumidamente, a reportagem aponta o último relatório da Organização das Nações Unidas para a Educação, a Ciência e a Cultura (Unesco), que demonstrava a importância de se intensificar a atenção para os problemas ambientais na educação. Traz a fala da coordenadora de educação da Unesco no Brasil e demarca que foi feita uma formação para professores com foco nas mudanças climáticas. Por fim, apresenta que:

[...] esse é o objetivo da Plenarinha deste ano, projeto que foi estendido a toda a rede pública de ensino do Distrito Federal. As crianças matriculadas na educação infantil estão discutindo o tema central A cidade e o campo que queremos." (UNESCO..., 15.09.2016).

Informa ainda que a culminância do projeto, segundo o subsecretário de educação básica, ocorreria na semana seguinte, com uma apresentação na Câmara Legislativa.

\begin{abstract}
A ideia [...] é dar voz a elas e deixá-las levar as próprias demandas ao Legislativo. "A essência do projeto é ensinar que eles têm direitos e deveres e, quando exercem os direitos e cumprem os deveres, tornam-se cidadãos melhores", completa. No Jardim de Infância da 312 Norte, a cidade que as crianças querem é livre do mosquito aedes aegypti. [...] "A gente fez uma casa para aprender a cuidar da casa de todo mundo. Não pode deixar água parada”, ensina Samira Lira Alvarenga, 5 anos. Camilly Vitória da Silva, 5, sabe todas as doenças que o mosquito pode transmitir: dengue, chicungunha e zikavírus. (UNESCO..., 15.09.2016).
\end{abstract}

A notícia no jornal permite indicar como o tema das Plenarinhas, realizadas em 2016 e 2017, aproxima-se da solicitação da Unesco. Atendendo ou não a uma solicitação específıca, com um tema então verticalizado, é interessante identificar que a fala das crianças ilustram a reportagem, de forma a legitimar que realmente ocorreram os momentos de discussão com os pequenos. Para além disso, o confronto da fala das crianças com o Informativo Epidemiológico de Dengue, Chikungunya e Zika, que aponta 23.091 casos suspeitos de Dengue no Distrito Federal (INFORMATIVO..., 2016, n. 38), permite aqui apontar que os pequenos, ao abordarem as doenças transmitidas pelo mosquito Aeds 
Aegypt, demonstram a sua inserção social, interpretando e produzindo opiniões acerca do problema enfrentado no Distrito Federal.

Pressupõe-se que todas as Plenarinhas têm como base de sua existência a escuta atenta e sensível às crianças, conforme reforçam a Subsecretária de Educação Básica e a Coordenadora de Educação Infantil, na apresentação da publicação Eu-Cidadão, da Plenarinha à Participação, que faz uma compilação das falas de algumas das crianças que participaram da II Plenarinha, por meio da transcrição e de seus desenhos. A publicação foi dividida em treze seções, coadunando com o disposto na Constituição Federal (BRASIL, 1988), acerca dos deveres do Estado e no Estatuto da Criança e do Adolescente, no que concerne aos direitos das crianças, como pode ser observado na explicação que acompanha cada seção. Em uma rápida olhada para a amplitude de temas debatidos com as crianças e para o caráter de reforço dos direitos e da cidadania, é possível apontar que, naquele momento, a intenção se aproxima mais de um diálogo com as crianças, a partir dos direitos apresentados, do que uma mudança curricular a partir do que elas expressaram.

Considerando que a criança é um sujeito participativo e protagonista de sua própria história, realizou-se, nos anos de 2013 e 2014, em toda a Rede Pública e Conveniada da SEEDF, a "Plenarinha da Educação Infantil”, que teve a intenção de incentivar os docentes a desenvolverem práticas pedagógicas para a escuta sensível e atenta às crianças, de forma a considerar a percepção delas acerca das situações que vivenciam na escola e na cidade, em interlocução com o Plano Distrital pela Primeira Infância - PDPI. 0 resultado foi surpreendente! Crianças sábias e cheias de imaginação na resolução de problemas encontrados. (EU-CIDADÃO, 2014, s/p).

No trecho fica implícita a indicação da Plenarinha como uma prática direcionada aos docentes, para que eles aprendam como devem escutar as crianças. Tomando apenas essa publicação síntese das falas das crianças, fica difícil identificar como realmente foram ouvidas. Contudo, compactuando com o que Chartier (1990) pontua acerca da relação travada entre aquilo que o autor escreve, o que se edita e publica, e a leitura que o leitor faz ao final, uma interpretação que toma a história de um texto ou de um livro "deve ser, antes de mais, reconstituição das distâncias nas práticas. Logo uma história do ato de ler". (CHARTIER, 1990, p. 136) Quando se volta para a Plenarinha no Distrito Federal, tomando sua orientação escrita e publicizada por meio de documentos oficiais, podese tomá-la à luz de uma história das práticas culturais e, como tal, considerar todas as possíveis "intrincações e reconstituir trajetórias complexas, da palavra proferida ao texto escrito, da escrita lida aos gestos feitos, do livro impresso à palavra leitora”. (CHARTIER, 1990, p. 136).

Outro aspecto que se torna evidente no trecho citado refere-se às perspectivas adultas diante das competências das crianças. 0 fato de serem surpreendidas pelas resoluções encontradas pelas crianças demonstra que os adultos não as consideram, de fato, enquanto atores sociais com capacidade de agência. 0 modelo de competência é pautado pela chegada na vida adulta enquanto etapa final do desenvolvimento humano, o que coloca as crianças em situação de inferioridade e incapacidade por ainda não estarem 
prontas para assumir responsabilidades enquanto integrantes da sociedade. (HUTCHBY; MORAN-ELLIS, 1998).

Essas questões demandam refletir acerca da compreensão da competência e das condições de escolha que as crianças têm, pois ao focar no preparo das crianças para o exercício da cidadania quando forem adultas, nega o direito de exercê-lo enquanto ainda são crianças uma vez que, além do direito da provisão e proteção, também lhes foi garantido o da participação, conforme previsto pela Convenção sobre os direitos da criança da Organização das Nações Unidas (ONU, 1989). Se os projetos partem do princípio da participação infantil, e recuperando a etimologia da palavra, que deriva do latim participatio, que significa tomar parte, em situações nas quais as crianças encontrarem abertura e participar dos assuntos que as afetam diretamente, não é de se surpreender que assim elas o farão. Diante da oportunidade, as crianças contrapõem a participação simbólica prevista pelos adultos e validam a capacidade de "decidirem, analisarem, interpretarem, questionarem, proporem, atuarem [...] e de falarem por si mesmas”. (OLIVEIRA, 2017, p. 162).

A indicação da existência de interlocução com o Plano Distrital pela Primeira Infância (PDPI), do Distrito Federal, direciona a questão a respeito da escuta sensível e atenta às crianças para o referido documento. Ainda nas primeiras páginas lê-se "de crianças para crianças - e com uma ajudinha dos adultos -, apresentamos o Plano Distrital pela Primeira Infância" (PLANO..., 2013, p. 10). Se é claro o reforço no papel de fala dado à criança, fica evidente que a função do adulto está atrelada e reforçada no processo do discurso e escuta dos pequenos. Parece algo lógico, uma vez que as crianças pequenas que frequentam a educação infantil não escrevem, portanto, não deixam marcas legitimadas na sociedade como representações de sua fala. Ou, como sinaliza Becchi (2010, p. VI), "o conhecimento da criança no presente e a reconstrução da história da infância no passado podem ser inseridos nesse quadro, que é de incerteza discursiva, de início de conhecimento, de difícil identificação do objeto a ser tratado", que acaba exigindo das pessoas que com ela lidam, "a mobilidade do olhar e a sensibilidade da audição". Nesse sentido, acompanhamos as falas das crianças por meio da apropriação, registro e transcrição feita pelos adultos. E como foram deixadas essas marcas, considerando as crianças do Distrito Federal? Seguindo o disposto no PDPI, a escuta à criança considera que:

A formulação de políticas públicas para primeira infância no DF adota, com o advento da Secretaria da Criança, um viés inovador: o reconhecimento de que o "ser criança" é mais bem compreendido por quem é criança. Ou seja, os adultos podem imaginar o que crianças querem e necessitam, mas ninguém melhor que elas para dizer exatamente o que querem; e existem técnicas que possibilitam a compreensão dos adultos sobre o que querem as crianças. Dessa forma, o foco da intervenção parte da criança e não do adulto: nós, adultos, que temos que tentar compreender a linguagem e necessidades das crianças, e não elas mudarem suas vivências de acordo com os anseios dos adultos. Assim, no processo de formulação de políticas públicas e normativas, temos a possibilidade de construir instrumentos que atingem as reais necessidades de crianças de 0 a 6 anos. As recomendações das crianças são o pilar do Plano Distrital pela Primeira Infância. Portanto, como protagonistas de suas histórias, nada mais justo que iniciarmos por elas. (PLANO..., 2013, p. 17, grifo nosso). 
0 plano trata da primeira plenária, a Plenarinha do Currículo (2013). Os números apresentados informam que 90 crianças, entre 4 e 6 anos de idade, participaram desse momento (PLANO..., 2013). Confrontando com o número de matrícula inicial na Educação Infantil naquele ano, eram 32.413 crianças matriculadas, na referida faixa etária (CADERNOS..., 2013, p. 254). Logo, 0,28\% das crianças da rede participaram da primeira escuta de sua opinião. Todavia, em documento posterior, o Currículo em Movimento da Educação Básica - Educação Infantil, publica que, em 2013, ocorreu a "Plenarinha do Currículo, ação que envolveu cerca de 400 crianças e 50 profissionais $^{3}$ das instituições públicas e conveniadas com o objetivo de dar vez e voz a nossos pequenos estudantes" (CURRÍCULO..., s/d, p. 13). Ao tomar o número em confronto com o de crianças matriculadas, sobe para 1,23\% a participação dos pequenos.

Aqui notam-se dois elementos importantes a serem considerados. 0 primeiro, em relação à forma como essa participação ocorre, a qual apresenta alguns questionamentos: quais crianças participam? Como elas são selecionadas para participar? Elas representam a diversidade das crianças presentes nas instituições de educação infantil? As propostas são trabalhadas anteriormente com elas? Como elas se organizam, entre pares, para solicitar suas necessidades? Espaços e tempos são previstos contínuos para essa participação? A participação das crianças na Plenarinha tem possibilitado o exercício de seus direitos? Essas questões retomam as possibilidades de participação ou de participação simbólica, elucidada por Hart (1992), ao pontuar que a participação é aprendida nos contextos em que são vividas.

Se a formação cidadã das crianças coloca-se como uma perspectiva da Plenarinha, envolvendo a escuta e fala dos pequenos, há de se requerer cenários democráticos e contextualizados acerca dos temas que serão discutidos com as crianças, em um processo que permita o exercício de sua autonomia e negociação com os adultos. Além disso, para despertar o interesse em participar, as crianças precisam que suas as ações sejam valorizadas, que "sua presença e participação tenham sentido, e que construam seu sentimento de pertença”. (AGOSTINHO, 2014, p. 1138).

0 segundo aspecto refere-se ao fato de dar a voz às crianças. Dar a voz significa permissão dada pelos adultos para que elas falem. Assim, a expressão indica uma lógica adultocêntrica que não as reconhece enquanto atores sociais. Qvrotrup (1990) pontua que ao rever o status da infância na sociedade, faz-se necessário ouvir a voz das crianças que já têm vozes, mas que historicamente não foram consideradas em condições de igualdade em relação aos demais grupos sociais. É preciso colocá-las como unidade de observação enquanto categoria geracional. Alderson (2005), por sua vez, ressalta a necessidade de reconhecer as crianças enquanto sujeitos que podem falar em direito próprio, considerando suas perspectivas em relação aos aspectos que afetam suas vidas. A respeito desse aspecto, James e Prout (1990) reforçam a importância de construir espaços de participação para que as crianças tenham suas vozes consideradas, que sejam estudadas enquanto sujeitos centrais, e que a atuação da criança na sociedade seja visibilizada e valorizada a partir da compreensão de seus direitos, enquanto atores sociais com voz.

3- Tal quantidade também comparece no guia da III Plenarinha. (GUIA..., 2015, p. 04). 
Ouvir as vozes das crianças tem sido uma expressão frequentemente utilizada, mas que reivindica a construção de uma sociedade que possibilite aos sujeitos exercitarem seus direitos essenciais e que, por meio de diálogos geracionais, possam considerar as singularidades tanto das crianças quanto dos adultos que da sociedade participam. (AGOSTINHO, 2014).

Quanto às técnicas utilizadas, o documento informa que o processo de consulta teve quatro princípios como base: "dar tempo e espaço para as suas ações individuais e conjunturas; criar um ambiente de ludicidade e de expressão; ter um olhar e uma escuta atentos e sensiveis; falar e olhar para a criança na sua altura” (PLANO..., 2013, p. 18). 0 quadro a seguir apresenta o processo de escuta:

Quadro 2 - Estratégias para a escuta à criança

\begin{tabular}{|c|c|}
\hline Estratégias & $\begin{array}{l}\text { • Roda de conversas } \\
\bullet \text { Brincadeiras } \\
\bullet \text { Oficinas lúdicas } \\
\text { - Registro fotográfico feito pelas crianças } \\
\bullet \text { Entrevistas }\end{array}$ \\
\hline Registro Usado & $\begin{array}{l}\text { - Escrito } \\
\text { - Gráfico } \\
\text { - Fotográfico } \\
\text { - Audiovisual }\end{array}$ \\
\hline $\begin{array}{c}\text { Materiais/equipamentos } \\
\text { para registro }\end{array}$ & $\begin{array}{c}\text { • Bloco de anotações e caneta } \\
\text { • Máquina fotográfica } \\
\text { • Gravador } \\
\text { • Filmadora } \\
\text { - Sulfite, caneta, lápis de cor, caneta hidrocor }\end{array}$ \\
\hline Como ocorreu o registro & $\begin{array}{l}\text { - Registro escrito através de palavras-chave } \\
\text { - Registro detalhado a partir dos principais comentários e falas } \\
\text { - Registro escrito a partir das fotografias tiradas nas atividades } \\
\text { - Registro escrito a partir das gravacõos }\end{array}$ \\
\hline
\end{tabular}

Fonte: PDPI, 2013.

Rocha (2008) alerta que a escuta da criança pelo adulto, ainda que utilize de metodologias diversas e que considere suas múltiplas linguagens, sempre passará por uma interpretação. Essa análise, que será feita por adultos, estará em consonância, segundo a autora, com as próprias intenções que estão postas na ação comunicativa e que esbarram nos limites de compreensão que os adultos podem alcançar diante do que as crianças dizem.

Outro aspecto a ser considerado, no que tange às escolhas metodológicas na escuta das crianças, refere-se aos modos de como serão incorporadas as falas das crianças nas decisões e nos textos publicados sobre o desenvolvimento do projeto. A ilusão de trazer a voz das crianças, nas ações desenvolvidas com elas, foi ressaltada por Llobet (2011) e Szulc et al. (2009), quando apontam que os dizeres das crianças têm sido utilizados de forma frequente para decorar os textos e ilustrar a participação das crianças. Essas falas, 
muitas vezes, são trazidas de forma descontextualizada e sem incorporar as experiências e os discursos das crianças de forma ampliada acerca da temática discutida. Segundo as autoras, o uso ilustrativo dessas falas desrespeita as crianças, enquanto interlocutoras, e prejudica a efetivação do direito da participação ativa, colocando-se como obstáculo para as transformações almejadas pelas crianças no exercício de sua cidadania.

Para que a participação das crianças não seja decorativa ou simbólica, faz-se necessário assumi-las enquanto produtoras de conhecimento e reconhecer suas formas de comunicação como legítimas. As maneiras de escutá-las devem ter em vista o estabelecimento de relações que contribuam "para renovar e reforçar os laços sociais nas comunidades em que participam” (FERREIRA, 2010, p. 157). Querer ouvir as crianças é reconhecer que as opiniões, os sentimentos, as ideias, as experiências e as perspectivas constituem a voz que elas já têm. (DEMETRIO; BODENMULLER; AGOSTINHO, 2015).

Cabe mencionar nesta discussão as contribuições de Foucault (1979), quando pontua que o poder se dá por meio de uma rede de relações que são instituídas direta e indiretamente entre os envolvidos. Assim, para que a participação seja significativa, faz-se necessário rever os contextos em que ela ocorre, bem como garantir que o poder possa ser compartilhado entre os participantes. Esse compartilhamento visa, portanto, a equilibrar os pontos de vista e adotar relações intergeracionais mais horizontais.

Os instrumentos utilizados para realizar a escuta, além de prever as diversas formas como as crianças se comunicam, precisam também incorporar estratégias que oportunizem tomadas de posição, que reconheçam a inteligibilidade das crianças e modifiquem os contextos. Deste modo, o registro torna-se essencial enquanto ferramenta que permite a retomada de perspectivas com as crianças, colocando-se como documentação que demonstra os percursos percorridos e memória do que já foi discutido, viabilizando que tanto os adultos quanto as crianças possam se orientar na decisão das ações que serão implementadas. (RINALDI, 2012).

Tendo em vista as discussões e registros realizados com os pequenos, o Plano Distrital pela Primeira Infância (PDPI) descreve quais foram as recomendações das crianças a respeito de: família e comunidade, saúde e alimentação, o brincar, escola e educação, mídias e tecnologias, violências e medos. Todos os temas são pertinentes de análise, todavia, aqui vamos nos voltar para dois: o brincar e escola e educação.

0 quadro, apesar de extenso, é pertinente para a rápida visualização do que se pede (enquanto criança) e do que se atende (enquanto adulto e poder do Estado). Oito foram as solicitações elencadas pelas crianças quanto ao brincar. Nota-se que todas consideram a questão do espaço como base de suas solicitações e não é qualquer espaço dentro de uma estrutura arquitetônica, e sim o espaço ao ar livre, aquele que permite atividades que possam tomar os elementos da natureza, como árvores, folhas, frutas. Apesar do importante papel docente, a brincadeira infantil que se organiza de forma independente do adulto possibilita que a criança exerça papéis sociais, reiterando e criando elementos culturais. No entanto, ao se pensar as ações de retorno às falas das crianças, o espaço que seria construído, para além dos parques, foi a brinquedoteca, descrita como "um espaço 
lúdico de interação e criatividade”. Seria possível apontar uma compreensão destoante entre o que foi dito e o que foi compreendido e, acima de tudo, proposto como meta?

Quadro 3 - Transcrição das ideias infantis

\begin{tabular}{|c|c|}
\hline 0 brincar & Escola e educação \\
\hline Pedido das crianças & Pedido das crianças \\
\hline $\begin{array}{l}\text { - Construir brinquedos novos e diferentes } \\
\text { - Dar brinquedos para as crianças que não } \\
\text { têm } \\
\text { - Espaço grande para pular e correr } \\
\text { - Árvores para subir } \\
\text { - Folhas, frutinhas para brincar de comidinha } \\
\text { - Brincar de subir, pular e escorregar } \\
\text { - Ter parque para ter mais espaço para fazer } \\
\text { o parque } \\
\text { - Tirar sujeira do parque para poder brincar } \\
\text { melhor }\end{array}$ & $\begin{array}{l}\text { - Ajudar as crianças a irem para a escola } \\
\text { - Deveria ser colorida } \\
\text { - Deveria ter uma piscina com tobogã e uma quadra com grama } \\
\text { - Ter mais plantas } \\
\text { - Ter mais brinquedos } \\
\text { - Ter uma escada para escalar } \\
\text { - Escola aberta e grande para ter mais espaço para correr } \\
\text { - Ter escolas perto das casas }\end{array}$ \\
\hline Metas do Plano & Metas do Plano \\
\hline $\begin{array}{l}\text { - Desenvolver um programa distrital com } \\
\text { parâmetros técnicos para a construção e } \\
\text { criação de brinquedotecas e parques infantis } \\
\text { para atender crianças. } \\
\text { - Abrir editais que visem selecionar, apoiar } \\
\text { e incentivar projetos culturais, sociais e } \\
\text { acadêmicos que forem executados dentro das } \\
\text { brinquedotecas públicas. } \\
\text { - Ampliar a oferta de brinquedoteca e parques } \\
\text { infantis nas cidades em três anos. } \\
\text { - Ofertar cursos para professores e demais } \\
\text { profissionais que trabalham em brinquedotecas } \\
\text { com diretrizes especificas voltadas para o } \\
\text { direito e a importância do brincar de todas as } \\
\text { crianças. }\end{array}$ & $\begin{array}{l}\text { - Ampliar a oferta de vagas na creche e universalizar as matrículas na pré-escola. } \\
\text { - Estimular instituições educacionais para que agreguem ou ampliem em suas práticas } \\
\text { pedagógicas cotidianas ações que visem o enfrentamento da violência sexual, a inclusão e } \\
\text { o respeito às diversidades, a promoção da saúde e dos cuidados, a adoção da cultura de paz } \\
\text { e convivência escolar e o estreitamento da relação famílias-crianças-instituição. } \\
\text { - Promover a igualdade de oportunidades educacionais entre as crianças de diferentes } \\
\text { classes sociais, territórios geográficos e etnias, expandindo o acesso aos bens culturais e } \\
\text { às possibilidades de vivência da infância. } \\
\text { - Ampliar e fortalecer políticas públicas permanentes de formação continuada de } \\
\text { professores/as e demais profissionais que atuam na Educação Infantil. } \\
\text { - Enriquecer e regionalizar a alimentação escolar, respeitadas as peculiaridades dos bebês } \\
\text { e das crianças pequenas. } \\
\text { - Prover e descentralizar recursos financeiros para que as instituições educacionais } \\
\text { adquiram materiais didático pedagógicos e afins respeitando as especificidades de cada } \\
\text { faixa etária. } \\
\text { - Garantir o acesso, a permanência e a qualidade de atendimento das crianças de } 6 \text { anos } \\
\text { no Ensino Fundamental. Ampliar o atendimento educacional em jornada de tempo integral. } \\
\text { - Ampliar o atendimento da Educação Precoce e de outros atendimentos da Educação } \\
\text { Inclusiva voltada para crianças com deficiências, transtornos globais de desenvolvimentos } \\
\text { e altas habilidades. } \\
\text { - Garantir o acesso a creches para crianças em situação de vulnerabilidade e risco social. }\end{array}$ \\
\hline
\end{tabular}

Fonte: PDPI, 2013.

Em se tratando do tema Escola e Educação, as crianças destacaram oito pontos importantes. Novamente, tem-se o espaço como base, com elementos específicos apontados - piscina, escada, plantas, brinquedos. Apesar de não termos elementos da discussão travada com as crianças, a existência de duas estruturas tão específicas - piscina e escada 
- nos permite vislumbrar a circulação entre elas e, a partir das interações que travaram, de possíveis elementos interessantes para o espaço educativo. A piscina é uma estrutura que faz parte de alguns Jardins de Infância do Distrito Federal, mas não de todos. Logo, saber de sua existência em algum Jardim de Infância - seja por ter frequentado por um tempo, escutado de alguém, por ter piscina em casa, por já ter ido a uma piscina e ser esse seu objeto de desejo, ou outra forma - é algo que demonstra como as ideias circulam entre os pequenos e como os mesmos se apropriam e produzem repertório para indicar suas vontades. Continuando, as duas solicitações relacionadas com a democratização do acesso à educação infantil - ajudar crianças a ir para a instituição educativa e ter instituições perto de casa - foram contempladas na meta que toma a ampliação da oferta. No que concerne ao pedido de que "a escola deveria ter mais brinquedos", é possível indicar a meta de provimento e descentralização de recursos financeiros para aquisição de "materiais didáticos pedagógicos" e, na lista, estavam os brinquedos.

Após a leitura da documentação acerca das Plenarinhas, é possível identificar que são construídas com dois focos: um para servir de orientação para as professoras e professores da educação infantil e outra de compilação das falas das crianças. Como orientação, os guias têm o mesmo direcionamento da ação docente:

[...] a observação, a escuta e o registro dos trabalhos produzidos pelas crianças. Esses elementos se fazem importantes porque a criança aprende, se relaciona, se comunica e se expressa por múltiplas linguagens, especialmente pelo brincar. (GUIA..., 2015, p. 12).

0 documento continua sempre reforçando que:

[...] significa dizer que necessitamos ter a sensibilidade para ouvir, observar e captar os diferentes símbolos, códigos e linguagens: oral, gráfica (desenhos, pinturas e escrita), audiovisual, lúdica, corporal, musical e artística que as crianças usam para se expressar. (GUIA..., 2015, p. 12).

A escuta sensível às crianças poderia reverberar em outros projetos, tal como apresentam Momo e Martínez (2017) ao considerarem a cultura da mídia e do consumo em quatro instituições de educação infantil no Distrito Federal. Ao tratarem das estratégias desenvolvidas por uma das professoras, as autoras recuperam um projeto anterior enviado pela Secretaria de Educação (SEEDF), que era um dos temas da II Plenarinha, de 2014. Elas escrevem que "quando a escola dessa professora recebeu, por parte da Regional de Ensino, o tema a ser trabalhado, nenhuma outra professora se dispôs a desenvolvê-lo com as crianças”. (MOMO; MARTINÉZ, 2017, p. 176). E continuam:

A partir daí, [a professora] foi criando e proporcionando um conjunto de situações, vivências e atividades que tinham como principais objetivos conhecer a relação das crianças com a cultura da mídia e do consumo e problematizar essa cultura. Assim, iniciou o projeto com atividades lúdicas a partir da música intitulada Videotinha, de Bia Bedran, como cantar, dançar, interpretar a letra da música, dramatizar e criar, com materiais reciclados, uma Videotinha. Uma das estratégias utilizadas foi possibilitar que as crianças fizessem desenhos sobre o que gostavam de ver na 
televisão. A partir da análise dos desenhos e de outras informações, a professora, em conjunto com as crianças, montou gráficos sobre os programas que as crianças mais gostavam de ver na televisão. Explorou esses gráficos com as crianças, realizando atividades orais de quantificação e de comparação entre as quantidades, assim colaborando para a aprendizagem de conhecimentos matemáticos. Durante essas atividades, a professora foi percebendo que a relação da cultura da mídia com a cultura do consumo era mesmo muito presente nas expressões verbais das crianças e em suas representações gráficas. Ela propôs, então, uma atividade na qual as crianças deveriam não somente desenhar o que mais gostavam de ver na televisão, mas também narrar o que gostavam. (MOMO; MARTINÉZ, 2017, p. 176).

Observa-se que a professora segue a escuta adequada da criança com base protocolar aqui já apresentada no quadro Estratégias para a escuta à criança. Todavia, como as autoras evidenciam, foi uma escolha da professora e não de todas as que pertenciam àquela unidade. Continuando, as autoras informam que a professora:

Disse que o projeto havia sido marcante, obtendo o reconhecimento dos colegas e da gestão escolar e até alcançando visibilidade em todo o DF, uma vez que algumas das atividades desenvolvidas por ela com as crianças foram publicadas no livro Trabalho Coletivo das crianças da Educação Infantil do Distrito Federal: Eu-cidadão da plenarinha à participação. (MOMO; MARTINÉZ, 2017, p. 179).

Os dois trechos aqui apresentados do estudo das autoras ajudam a perceber os possíveis desdobramentos de práticas docentes coletivas ou individuais, que proporcionam momentos de fala e de escuta à criança e, posteriormente, como que essas falas comparecem no material específico sobre a Plenarinha. Contudo, as falas das crianças, colhidas durante os momentos da Plenarinha, também podem ser encontradas em outro tipo de documentação, como a Proposta Pedagógica (PP). Em uma delas, encontra-se o seguinte enunciado: "quero que a minha escola viva para sempre", dita por Mariana, de 4 anos, "retirada da Plenarinha/2018" (PROPOSTA..., 2019, p. 04). A referida era a VI Plenarinha - Universo do Brincar. No guia de orientação aos professores e professoras, o convite era para refletir e compreender que "é por meio do brincar que a criança vivencia o poder de experimentar o mundo dos objetos, das pessoas, da natureza e da cultura, para compreendê-lo e expressá-lo em suas mais variadas linguagens [...]" (PLENARINHA, 2018, p. 07). Na fala recortada e que ilustra o início da Proposta Pedagógica do Jardim de Infância, a pequena Mariana não tratou especificamente do brincar, mas sua participação indica um raciocínio articulado com sua vivência naquele espaço, apresentando um desejo de que ele continue assim, do jeito que é, para o tempo que indica eterno: "para sempre". Se é consensuado que durante a brincadeira a criança tem um momento importante para constituir e entender sua forma de estar e pensar o mundo, uma Plenarinha específica sobre o brincar pode permitir que não se tenham respostas somente direcionadas para a temática, mas que contemplam um pensamento mais elaborado diante do brincar como práxis social infantil. 
A VI Plenarinha também é apresentada ao público em geral e a especialistas por meio de dois vídeos disponibilizados na plataforma Youtube ${ }^{4}$. Neles é possível acompanhar as falas das crianças e a da narradora, que contrapõe as imagens e falas com uma discussão teórica. Para além do teor didático, que pode ser direcionado para os(as) atuais e futuros(as) docentes, os posicionamentos das crianças estão condizentes com o tema do brincar. Nenhuma delas fez uma fala como a da Mariana, de seu desejo de continuidade da sua "escola". É claro que isso passa pela escolha do que se edita, do que se interpreta e se publiciza diante de um tema específico. 0 vídeo assim como outros documentos contribuem para a percepção do funcionamento da Plenarinha, contando com a fala de diferentes partícipes da educação infantil na rede.

\section{Fechamento de ideias, apontamento de outras}

Considerar a Plenarinha enquanto instrumento legítimo de participação demanda avançar no atendimento das reais necessidades das crianças, em sua pluralidade e diversidade, para que se reconheça quem são as crianças envolvidas no processo de escuta. Além de solicitar que se leve em consideração os lugares que ocupam na vida social e proporcionar mudanças nos espaços educativos atendendo o que foi dito, solicitado e discutido com os pequenos.

As crianças têm muito a dizer e, para que essa voz não apenas ilustre as propostas desenvolvidas com elas, exige-se um exercício contínuo a ser praticado entre adultos e crianças e que, segundo Tomás (2007), envolve o empoderamento de ambos para que juntos alcancem um objetivo comum em parceria, sendo fundamental que as crianças possam adquirir valores, normas e conteúdos que servirão de apoio para experiência cívica.

Propostas como a Plenarinha demonstram avanços teóricos nos documentos publicados, entretanto, não trazem implicações para instituições de educação infantil. Notase que as discussões abordadas nos documentos oficiais contemplam a escuta sensível das crianças com vistas à participação, mas, possivelmente, não trazem transformações para a vida das crianças e tampouco modificam as ações no currículo, conforme previsto na proposta. A forma como foi realizado o projeto com as crianças nas instituições também não deixa claro como que elas foram ouvidas, se ocorreram em espaços democráticos e se houve diálogo vertical com os pequenos. Cabe mencionar ainda que o número de crianças e de professores que participaram na Plenarinha não contempla a quantidade de crianças que estão matriculadas na rede.

A Plenarinha coloca-se como um dispositivo inovador em considerar as crianças como sujeitos de direitos e protagonistas de suas vidas e insiste no discurso de dar voz e vez a elas, todavia, por meio dos documentos oficiais, não é possivel identificar as contribuições das crianças enquanto ações efetivas nas instituições de educação infantil do Distrito Federal. Os documentos publicados trazem a fala das crianças para reforçar hipóteses ou pontuar elementos que demonstram a participação, mas que foram selecionados pelos

4- Um deles intitulado Plenarinha 2018 Universo do Brincar, disponível em: https://www.youtube.com/watch?v=0qUk3H0cETY\&t=5s. 0 outro, Plenarinha Universo do Brincar, disponível em: https://www.youtube.com/watch?v=JoKL3fj4-jY\&t=8s. Ambos acessados em 10 abr. 2020. 
adultos, sem considerar e apontar os contextos em que as falas das crianças foram ditas (PERCY-SMITH; THOMAS, 2010). De acordo com Rocha (1999), o fato de a criança ser vista e considerada nos projetos mais amplos não é suficiente para que ela ganhe voz e seja escutada, de forma a ter suas perspectivas consideradas pelos adultos.

Enquanto recurso formativo para os professores, o documento parece cumprir o propósito de que os adultos aprendam a desenvolver uma escuta sensível das crianças, o que indica novamente que elas ficam em segundo plano. A esse entendimento, pode-se dizer que o documento explicita o papel do adulto para que a participação infantil ocorra, colocando-o diante de um fazer pedagógico atento às contribuições que as crianças podem ofertar para os cenários que demandam por mudanças. Reconhece, ainda, que os professores precisam obter apoio com iniciativas como a Plenarinha, por exemplo, em todo o sistema educativo, envolvendo a maior quantidade e representatividade de crianças, docentes e instituições para que, de fato, a proposta seja inovadora e a participação não seja um elemento decorativo nos documentos oficiais.

Considerar a escuta enquanto metodologia e estratégia de trabalho com as crianças envolve tomada de posição diante do papel que elas assumem na sociedade e refere-se a um posicionamento político diante de um grupo minoritário, que historicamente teve sua voz invisibilizada. Sugere-se que a participação das crianças não seja considerada enquanto ações pontuais para o desenvolvimento de uma ação pedagógica ou uma intervenção para cidadania, pois essas atividades isoladas não superam os três degraus da escada, elaborada por Hart (1992), na qual existe uma intenção simbólica de que elas participem, quando na verdade não se pretende efetivá-las.

A participação ocorre e se constrói com o tempo, demanda aprendizagem e aperfeiçoamento, conduzida por práticas de observação e escuta. Deste modo, a participação não é apenas:

[...] um processo de escuta das crianças, de ouvir as suas vozes ou ter em conta as suas opiniões, experiências, medos, desejos e incertezas: sustenta a possibilidade de as crianças descobrirem e negociarem a essência de quem elas são e o seu lugar no mundo. (GRAHAM; FITZGERALD, 2010, p. 8).

\section{Referências}

AGOSTINHO, Katia. Adair. A complexidade da participação das crianças na educação infantil. Perspectiva, Florianópolis, v. 32, n. 3, p. 1127-1143, maio 2014.

ALDERSON, Priscilla. As crianças como pesquisadoras: os efeitos dos direitos de participação sobre a metodologia de pesquisa. Educação \& Sociedade, Campinas, v. 26, n. 91, p. 419-442, ago. 2005.

BECCHI, Egle. I bambini nella storia. Roma-Bari: Laterza \& Figli, 2010.

BRASIL. Constituição Federal de 1988. Brasília, DF [s. n.], 1988. Disponível em: http://www.planalto.gov. br/ccivil_03/constituicao/constituicao.htm. Acesso em: 10 jun. 2020. 
CADERNOS de matrícula. Brasília, DF, Secretaria de Estado de Educação do Distrito Federal, 2015.

CHARTIER, Roger. A história cultural: entre práticas e representações. Tradução de Maria Manuela Galhardo. Rio de Janeiro: Difel, 1990.

CURRÍCULO em movimento da educação básica: educação infantil. Brasília, DF: Secretaria de Estado de Educação do Distrito Federal, [s. d.]. Disponível em: http://www.se.df.gov.br/curriculo-em-movimento-daeducacao-basica-2/ Acesso em: 04 abr. 2020.

DEMETRIO, Rúbia Vanessa Vicente; BODENMULLER, Sasky; AGOSTINHO, Katia Adair. Participação infantil: a busca por uma relação democrática entre crianças e adultos. Zero-a-Seis, Florianópolis, v. 17, n. 32, p. 224-239, out. 2015.

EU-CIDADÃO, da Plenarinha à participação. Brasília, DF: Secretaria de Estado de Educação do Distrito Federal, 2014.

FERREIRA, Manuela. "- Ela é nossa prisioneira!" Questões teóricas, epistemológicas e ético-metodológicas a propósito dos processos de obtenção da permissão das crianças pequenas numa pesquisa etnográfica. Revista Reflexão e Ação, Santa Cruz do Sul, v.18, n. 2, p. 151-182, jul./dez. 2010.

FOUCAULT, Michel. Microfísica do poder. Rio de Janeiro: Edições Graal, 1979.

FREIRE, Madalena Weffort. Observação, registro e reflexão: instrumentos metodológicos I. 2. ed. São Paulo: Espaços Pedagógicos, 1996.

GOMES, Anderson Severino. Assembleias do orçamento participativo da criança. In: GOMES, Anderson Severino et al. Orçamento participativo criança: exercendo a cidadania desde a infância. São Paulo: Instituto Paulo Freire, 2004. p. 01-185.

GRAHAM, Anne; FITZGERALD, Robyn. 0 progresso da participação das crianças: explorando o potencial de uma atitude dialógica. Childhood, Nova Gales do Sul, v.17, n. 3, p. 343-359, 2010. Southern Cross University ePublications@SCU.

GUIA da III Plenarinha. Módulo 1. Brasília, DF: Secretaria de Estado de Educação do Distrito Federal, 2015.

HART, Roger. Children's participation: the theory and practice of involving young citizens in community development and environmental care. London: Earthscan, 1992.

HUTCHBY, Ian; MORAN-ELLIS, Jo (ed.). Children and social competence: arenas of action. London, The Falmer Press, 1998.

INFORMATIVO EPIDEMIOLÓGICO DE DENGUE, CHIKUNGUNYA E ZIKA. Brasília, DF, v. 11, n. 38, set. 2016.

JAMES, Allison; PROUT, Alan. Constructing and reconstructing childhood: contemporary issues in the sociological study of childhood. London: The Falmer Press, 1990. 
KORCZAK, Janusz. Como amar uma Criança. Rio de Janeiro: Paz e Terra, 1983.

LLOBET, Valeria. Un mapeo preliminar de investigaciones sobre infancia y adolescencia em las ciencias sociales en Argentina desde mediados de la decada de 1990. Kairos, San Luis, v.15, n. 28, p. 1-20, 2011.

MOMO, Mariangela; MARTINÉZ, Albertina Mitjáns. 0 trabalho pedagógico criativo na educação infantil diante da cultura da mídia e do consumo. Educação em Revista, Belo Horizonte, v. 33, n. 02, p. 161-188, 2017.

OLIVEIRA. Fabiana de. Reflexões a respeito de uma experiência de participação infantil envolvendo os espaços urbanos e a perspectiva das crianças. Revista Portuguesa de Educação, Braga, v. 30, n. 1. p. 157-179, 2017.

OLIVEIRA, Sueli Machado Pereira de; REIS, Magali dos. Democracia e a participação da criança. Revista Arquivo Brasileiro de Educação, Belo Horizonte, v. 1, n. 2, p. 76-90, 2013.

ONU. Organização das Nações Unidas. Convenção sobre os Direitos da Criança de 1989. [S. I.]: ONU, 1989. Disponível em: https://www.unicef.org/brazil/convencao-sobre-os-direitos-da-crianca. Acesso em: 10 jun. 2020.

PERCY-SMITH, Barry; THOMAS, Nigel. Introduction. In: A HANDBOOK of children and young people's participation: perspectives from theory and practice. New York: Routledge Taylor \& Francis Group, 2010. p. 1-8.

PLANO distrital pela primeira infância. Brasília, DF: GDF, 2013. Versão preliminar para consulta pública, Brasília, GDF, 12 de outubro de 2013.

PROGRAMA Educação Infantil. Brasília, DF: Secretaria de Estado de Educação do Distrito Federal, [s. d.]. Disponível em: http://www.se.df.gov.br/plenarinha/. Acesso em: 04 de abr. 2020.

PROPOSTA Pedagógica. Jardim de Infância 308 Sul. Brasília, DF: Secretaria de Estado de Educação do Distrito Federal: Coordenação Regional de Ensino do Plano Piloto, 2019.

QVORTRUP, Jens. A voice for children in statistical and social accounting. In: JAMES, Allison; PROUT, Alan (org.). Constructing and reconstructing childhood: contemporary issues in the sociological study of childhood. London: The Falmer Press, 1990. p. 73-94.

RINALDI, Carla. A pedagogia da escuta: a perspectiva da escuta em Reggio Emilia. In: EDWARDS, Carolyn; GANDINI, Lela; FORMAN, George. As cem linguagens da criança. v. 2. Porto Alegre: Penso, 2016. p. 235-247.

RINALDI, Carla. Diálogos com Reggio Emilia: escutar, investigar e aprender. São Paulo: Paz e Terra, 2012.

ROCHA, Eloisa Acires Candal. A pesquisa em educação infantil no Brasil: trajetória recente perspectiva de consolidação de uma pedagogia da educação infantil. Universidade Estadual de Campinas (Unicamp), Campinas, 1999. 
ROCHA, Eloisa Acires Candal. Por que ouvir as crianças? Algumas questões para um debate científico multidisciplinar. In: CRUZ, Silvia Helena Vieira. A criança fala: a escuta de crianças em pesquisas. São Paulo: Cortez, 2008. p. 43-51.

SOUZA, Gizele de. A educação das crianças pequenas: a busca pela emancipação. In: SOUZA, Gizele de (org.) A criança em perspectiva: 0 olhar do mundo sobre o tempo infância. São Paulo: Cortez, 2007. p. 73-84.

SZULC, Andrea et al. La investigación etnográfica sobre y con niños y niñas: una mirada desde la antropología. In: CONGRESO DE LA ASOCIACIÓN LATINOAMERICANA DE SOCIOLOGÍA, 27., 2009, Buenos Aires. Actas del... Buenos Aires: [s. n.], 2009. p. 01-09

TAYLOR, Marilyn; PERCY-SMITH, Barry. Children's participation: learning from and for community development. International Journal of Children's Rights, Netherlands, v. 16, n. 1, p. 379-394, 2008.

TOMÁS, Catarina. Participação não tem Idade. Revista Contexto \& Educação, ljuí, Rio v. 22, n. 78, p. 45-68, 2007.

UNESCO quer que as escolas intensifiquem atenção aos problemas ambientais. Correio Braziliense, Caderno Cidades, 15 out. 2016. Disponível em: https://www.correiobraziliense.com.br/app/noticia/ cidades/2016/09/15/interna_cidadesdf,548808/unesco-quer-que-escolas-intensifiquem-atencao-aosproblemas-ambientais.shtml. Acesso em: 05 jun. 2020.

PLENARINHA da Educação Infantil. A criança do Distrito Federal e o direito ao brincar, 6., 2018, Brasília, DF. VI Plenarinha... Brasília, DF: Secretaria de Estado de Educação do Distrito Federal, 2018.

WYNESS, Michael. Mapping out the field of children's participation: Definitions, narratives and disputes. In: BELLONI, Maria Carmen, BOSISIO, Roberta, OLAGNERO, Manuela (ed.). Becoming children: well-being, participation, citizenship. Torino: Accademia University Press, 2016. p. 44-58.

Recebido em: 16.04.2020

Revisado em: 02.06.2020

Aprovado em: 30.06.2020

Etienne Baldez Louzada Barbosa é doutora em educação pela Universidade Federal do Paraná. Pesquisadora do Núcleo de Estudos e Pesquisa em Infância e Educação Infantil (NEPIE/ UFPR). É professora adjunta da Faculdade de Educação e do Programa de Pós-Graduação em Educação Mestrado Profissional, da Universidade de Brasília.

Monique Aparecida Voltarelli é doutora em educação pela Universidade de São Paulo. Pesquisadora do Grupo de Estudos e Pesquisa sobre Sociologia da Infância e Educação Infantil (GEPSI/FEUSP). É professora adjunta da Faculdade de Educação e do Programa de Pós-Graduação em Educação Mestrado Profissional, da Universidade de Brasília. 